Article

\title{
Combined Evaluation of Geriatric Nutritional Risk Index and Modified Creatinine Index for Predicting Mortality in Patients on Hemodialysis
}

\author{
Takahiro Yajima ${ }^{1, * \mathbb{D}}$, Kumiko Yajima $^{2}$ and Maiko Arao ${ }^{1}$ \\ 1 Department of Nephrology, Matsunami General Hospital, Gifu 501-6062, Japan; matsunamijinzou@gmail.com \\ 2 Department of Internal Medicine, Matsunami General Hospital, Gifu 501-6062, Japan; \\ green_tea_1324@yahoo.co.jp \\ * Correspondence: yajima5639@gmail.com; Tel.: +81-58-388-0111
}

Citation: Yajima, T.; Yajima, K.; Arao, M. Combined Evaluation of Geriatric Nutritional Risk Index and Modified Creatinine Index for Predicting

Mortality in Patients on

Hemodialysis. Nutrients 2022, 14, 752. https://doi.org/10.3390/

nu14040752

Academic Editor: Sara C. Folta

Received: 7 January 2022

Accepted: 8 February 2022

Published: 10 February 2022

Publisher's Note: MDPI stays neutral with regard to jurisdictional claims in published maps and institutional affiliations.

Copyright: (c) 2022 by the authors. Licensee MDPI, Basel, Switzerland. This article is an open access article distributed under the terms and conditions of the Creative Commons Attribution (CC BY) license (https:/ / creativecommons.org/licenses/by/ $4.0 /)$.

\begin{abstract}
The geriatric nutritional risk index (GNRI) and modified creatinine index (mCI) are surrogate markers of protein-energy wasting in patients receiving hemodialysis. We aimed to examine whether a combined evaluation of these indices improved mortality prediction in this population. We retrospectively investigated 263 hemodialysis patients divided into two groups, using 91.2 and $20.16 \mathrm{mg} / \mathrm{kg} /$ day as cut-off values of GNRI and $\mathrm{mCI}$, respectively. The resultant four groups were reshuffled into four subgroups defined using combinations of cut-off values of both indices and were followed up. During the follow-up period (median: 3.1 years), 103 patients died (46/103, cardiovascular causes). Lower GNRI and lower mCI were independently associated with all-cause mortality (adjusted hazard ratio (aHR) 4.96, 95\% confidence intervals (CI) 3.10-7.94, and aHR 1.92, 95\% CI 1.22-3.02, respectively). The aHR value for the lower GNRI and lower $\mathrm{mCI}$ group vs. the higher GNRI and higher mCI group was 7.95 (95\% CI 4.38-14.43). Further, the addition of GNRI and mCI to the baseline risk assessment model significantly improved the C-index of all-cause mortality (0.801 to $0.835, p=0.025$ ). The simultaneous evaluation of GNRI and $\mathrm{mCI}$ could be clinically useful to stratify the risk of mortality and to improve the predictability of mortality in patients on hemodialysis.
\end{abstract}

Keywords: geriatric nutritional risk index (GNRI); modified creatinine index (mCI); hemodialysis; protein-energy wasting (PEW); all-cause mortality

\section{Introduction}

Protein-energy wasting (PEW) is a common malnutritional form that is characterized by a loss of fat and muscle mass caused by chronic inflammation and is related to an increased risk of all-cause mortality in patients receiving hemodialysis (HD) [1]. Several assessment methods of nutrition have been employed for the evaluation of PEW in this population. The malnutrition inflammation score (MIS) is one of the most validated tools for evaluating patients on HD at a risk of malnutrition [2-4]. However, assessments by well-trained examiners are needed to obtain a consistent MIS [5]. Conversely, objective screening methods such as the geriatric nutritional risk index (GNRI) and the modified creatinine index $(\mathrm{mCI})$ are also frequently used for evaluating nutritional statuses in this vulnerable patient population [6-8]. While GNRI estimation is performed using the serum albumin level (Alb) and the body mass index (BMI) [6,9], $\mathrm{mCI}$ is calculated using parameters including age, sex, urea clearance $(\mathrm{Kt} / \mathrm{V})$, and pre-hemodialysis serum creatinine level [7]. These objective indices are easily calculable using biochemical values obtained from routine blood tests. A meta-analysis concluded that GNRI is a clinically useful predictor of all-cause and cardiovascular mortality in HD patients [10]. Some studies have reported that $\mathrm{mCI}$ also correlates with both increased risks of cardiovascular events and with all-cause and cardiovascular mortality [11-13]. Moreover, Yamada et al. recently demonstrated that the predictive accuracy of GNRI for all-cause mortality was equal to that of $\mathrm{mCI}$ in patients 
on HD [14]. Furthermore, we recently demonstrated that a combination of GNRI and the erythropoietin resistance index or the extracellular/intracellular fluid ratio measured using bioimpedance analysis could improve the predictability of mortality risk in patients on HD $[15,16]$.

Therefore, we hypothesized that a combination of GNRI and $\mathrm{mCI}$ scores could be utilized to improve the predictive accuracy of mortality in patients receiving HD. The present study aimed to investigate whether a combined estimation of GNRI and $\mathrm{mCI}$ indices could improve the predictability of all-cause mortality risks in patients on HD.

\section{Materials and Methods}

\subsection{Study Population}

This retrospective cohort study enrolled 263 patients who underwent HD for $\geq 6$ months (with no hospitalization for at least the last 3 months) at the outpatient clinic of the Matsunami General Hospital (Kasamatsu, Gifu, Japan) between April 2008 and March 2021. Data were collated via retrospective chart review.

This study adhered to the guidelines of the Declaration of Helsinki and was approved by the ethics committee of the Matsunami General Hospital (Approval no. 504). The requirements of informed consent were waived because all patients' data were anonymized before access.

\subsection{Collection of Data}

Data of all study participants were obtained from their medical charts: age; sex; underlying renal disease (diabetic nephropathy, chronic glomerulonephritis, nephrosclerosis, and others); type of vascular access (arteriovenous fistula/graft or central venous catheter), HD vintage; alcohol and/or smoking habit; history of comorbidities (hypertension, diabetes mellitus, cardiovascular disease (atherosclerotic/ischemic heart disease, peripheral vascular disease, transient ischemic attack/cerebrovascular accident, congestive heart failure, other cardiac diseases endocarditis, myocarditis, pericarditis, cardiac devices, valve replacement, and heart transplantation, and dysrhythmia), lung disease (chronic obstructive pulmonary disease), liver disease, gastrointestinal bleeding, and cancer); height; dry weight; and use of RAS inhibitors or statins. In the present study, patients receiving antihypertensive medications, those with a diastolic blood pressure $\geq 90 \mathrm{mmHg}$, and those with a systolic blood pressure $\geq 140 \mathrm{mmHg}$ (measured before a HD session) were identified as having hypertension. Diabetes mellitus was recorded in those with a history of the disease and/or in those using glucose-lowering medications. The dialysis patient-specific comorbidity index including 11 comorbid conditions, which Liu et al. proposed, was scored as previously reported $[17,18]$. The assigned scoring weights were as follows: 1 point for diabetes and atherosclerotic/ischemic heart disease; 3 points for congestive heart failure; and 2 points for the remaining comorbidities. Blood tests were performed before the first HD session of the week, on either Monday or Tuesday.

\subsection{Calculation of Nutritional Indices and Patient Grouping}

The GNRI was calculated using the following formula [6,9]:

GNRI $=14.89 \times \mathrm{Alb}(\mathrm{g} / \mathrm{dL})+41.7 \times$ Dry weight $(\mathrm{kg}) /$ ideal body weight $(\mathrm{kg})\left(=\right.$ height $^{2}$ $\left.\left[\mathrm{m}^{2}\right] \times 22\right)=14.89 \times \mathrm{Alb}(\mathrm{g} / \mathrm{dL})+41.7 \times \mathrm{BMI} / 22$.

When $\mathrm{BMI}$ was $\geq 22 \mathrm{~kg} / \mathrm{m}^{2}$, the value of $\mathrm{BMI} / 22$ was considered as 1 .

The $\mathrm{mCI}$ was calculated using parameters including sex, age, spKt/V (for urea clearance), and pre-hemodialysis creatinine level using the following formula:

$\mathrm{mCI}(\mathrm{mg} / \mathrm{kg} /$ day $)=16.21+1.12 \times(0$ for woman; 1 for man $)-0.06 \times$ age $($ years $)$ $-0.08 \times \mathrm{spKt} / \mathrm{V}$ for urea $+0.009 \times$ pre-hemodialysis creatinine $(\mu \mathrm{mol} / \mathrm{L})$ [7] .

Patients were divided into 2 groups (high vs. low GNRI groups) using a cut-off GNRI value of 91.2, as reported previously [6]. They were also divided into 2 groups (high vs. low $\mathrm{mCI}$ groups) using the cut-off median $\mathrm{mCI}$ value of $20.16 \mathrm{mg} / \mathrm{kg} /$ day. Finally, the resultant 4 patient groups were redistributed into 4 subgroups according to a combination 
of the cut-off values of those indices: Group 1 (G1), high GNRI and high mCI; Group 2 (G2), high GNRI and low mCI; Group 3 (G3), low GNRI and high mCI; Group 4 (G4), low GNRI and low $\mathrm{mCI}$.

\subsection{Study Endpoint and Patient Follow-Up}

The study endpoint was all-cause mortality. Patients were included in the study from April 2008 to March 2020 and were followed up until March 2021. As per protocol, the follow-up period was defined as the time from the date of the blood tests (used for calculating the indices) to the date of either death or transfer to a renal transplantation or another HD facility. Surviving patients were censored in March 2021.

\subsection{Statistical Analysis}

Non-normally and normally distributed variables were expressed as medians (interquartile range) and as means \pm standard deviations, respectively. The differences among the four patient subgroups derived using a combination of cut-off GNRI and $\mathrm{mCI}$ values were compared using the Kruskal-Wallis test or a one-way analysis of variance for continuous variables and the Chi-squared test for categorical variables. The Kaplan-Meier method was used to evaluate the survival rates, and the log-rank test was used to compare the inter-group differences. Cox regression analysis was performed to calculate the hazard ratio (HR) and the $95 \%$ confidence intervals (CIs) for all-cause mortality. The multivariate Cox regression model was applied to variables reported to be established risk indicators for mortality in patients receiving HD. In this case, the type of vascular access, HD vintage, concurrent hypertension, use of RAS inhibitors or statins, comorbidity index, hemoglobin level, and $\log$ C-reactive protein (CRP) were included as covariates. Because serum Alb and BMI values were required for GNRI estimation and the patient's sex, age, urea clearance, and serum creatinine level were required for $\mathrm{mCI}$ calculation, these variables were excluded from the covariate analysis.

Regarding model discrimination, the C-index, which was defined as the area under the receiver operating characteristic curve in a logistic regression model, was calculated to investigate the predictive accuracy of all-cause mortality [19]. In this study, the C-indices were compared between a baseline risk model including the established classical risk factors and models of adding the GNRI alone, the $\mathrm{mCI}$ alone, and a combination of GNRI and $\mathrm{mCI}$. Furthermore, the net reclassification improvement (NRI) and the integrated discrimination improvement (IDI) were also calculated. The NRI is defined as the relative improvement of the number of patients for predicting mortality, whereas the IDI is defined as the average improvement of predicting mortality [20]. We used the IBM SPSS version 24 software (IBM Corp., Armonk, NY, USA) to perform the statistical analyses. A $p$-value less than 0.05 denoted statistical significance.

\section{Results}

\subsection{Baseline Characteristics of the Study Participants}

Data on the baseline characteristics of the participants are shown in Table 1. The mean age of the study population was $63.8 \pm 13.7$ years, and $66.5 \%$ of the participants were men. The types of vascular access comprised arteriovenous fistulas $(201 ; 76.4 \%)$, arteriovenous grafts $(58 ; 22.1 \%)$, and central venous catheters $(4 ; 1.5 \%)$. The dialysis vintage value was $1.5(0.7-4.3)$ years, with $94.3 \%$ and $47.1 \%$ patients having hypertension and diabetes, respectively. The comorbidity index was $4.4 \pm 3.6$. Furthermore, $57.8 \%$ and $44.1 \%$ of the patients were taking RAS inhibitors and statins, respectively. The mean BMI was $22.1 \pm 4.2 \mathrm{~kg} / \mathrm{m}^{2}$. The hemoglobin level, serum Alb, CRP, and spKt/V for urea were $10.6 \pm 1.4 \mathrm{~g} / \mathrm{dL}, 3.6 \pm 0.4 \mathrm{~g} / \mathrm{dL}, 0.15$ $(0.06-0.43) \mathrm{mg} / \mathrm{dL}$, and $1.34 \pm 0.29$, respectively.The GNRI and $\mathrm{mCI}$ values were $93.1 \pm 7.6$ and $20.2 \pm 3.0(20.16(17.87-22.18)) \mathrm{mg} / \mathrm{kg} /$ day, respectively. 
Table 1. Baseline patient characteristics.

\begin{tabular}{|c|c|c|c|c|c|c|}
\hline & $\begin{array}{l}\text { All Patients } \\
(N=263)\end{array}$ & $\mathrm{G} 1(N=102)$ & $\mathrm{G} 2(N=69)$ & G3 $(N=29)$ & $\mathrm{G} 4(N=63)$ & $p$-Value \\
\hline Age (years) & $63.8 \pm 13.7$ & $56.0 \pm 14.2$ & $66.8 \pm 9.1$ & $62.4 \pm 12.9$ & $73.8 \pm 9.5$ & $<0.0001$ \\
\hline Men $(\%)$ & 66.5 & 76.5 & 59.4 & 82.8 & 50.8 & 0.0009 \\
\hline Underlying renal disease & & & & & & 0.012 \\
\hline Diabetic nephropathy (\%) & 42.6 & 42.7 & 58.9 & 9.1 & 38.8 & \\
\hline Chronic glomerulonephritis (\%) & 29.6 & 31.3 & 14.3 & 54.5 & 32.7 & \\
\hline Nephrosclerosis (\%) & 20.2 & 19.8 & 16.1 & 27.2 & 22.4 & \\
\hline Others $(\%)$ & 7.4 & 6.3 & 10.7 & 9.1 & 6.1 & \\
\hline Type of vascular access & & & & & & 0.0097 \\
\hline Arteriovenous fistula (\%) & 76.4 & 80.4 & 71.0 & 89.7 & 69.8 & \\
\hline Arteriovenous graft (\%) & 22.1 & 19.6 & 29.0 & 10.3 & 23.8 & \\
\hline Central venous catheter (\%) & 1.5 & 0 & 0 & 0 & 6.3 & \\
\hline Hemodialysis vintage (years) & $1.5(0.7-4.3)$ & $3.7(1.2-6.2)$ & $1.0(0.7-2.0)$ & $2.5(0.8-5.5)$ & $0.8(0.6-1.7)$ & $<0.0001$ \\
\hline Alcohol $(\%)$ & 25.8 & 25.5 & 29.0 & 34.4 & 19.0 & 0.39 \\
\hline Smoking (\%) & 27.8 & 28.4 & 37.7 & 37.9 & 11.1 & 0.0035 \\
\hline Hypertension (\%) & 94.3 & 95.1 & 97.1 & 96.6 & 88.9 & 0.18 \\
\hline Comorbidity index & $4.4 \pm 3.6$ & $3.5 \pm 3.5$ & $5.6 \pm 3.5$ & $3.6 \pm 3.6$ & $4.9 \pm 3.3$ & 0.0007 \\
\hline Diabetes mellitus (\%) & 47.1 & 42.2 & 65.2 & 27.6 & 44.4 & 0.0021 \\
\hline Atherosclerotic/ischemic heart disease (\%) & 29.7 & 24.5 & 44.9 & 20.7 & 25.4 & 0.017 \\
\hline Peripheral vascular disease $(\%)$ & 14.1 & 10.8 & 20.3 & 10.3 & 14.3 & 0.34 \\
\hline $\begin{array}{c}\text { Transient ischemic attack/cerebrovascular } \\
\text { accident }(\%)\end{array}$ & 16.7 & 16.7 & 15.9 & 17.2 & 17.5 & 0.99 \\
\hline Congestive heart failure $(\%)$ & 57.4 & 44.1 & 72.5 & 48.3 & 66.7 & 0.0006 \\
\hline Other cardiac disease (\%) & 23.2 & 17.6 & 29.0 & 13.8 & 30.2 & 0.096 \\
\hline Dysrhythmia (\%) & 11.4 & 15.7 & 14.5 & 3.4 & 4.8 & 0.043 \\
\hline Chronic obstructive pulmonary disease (\%) & 3.4 & 2.0 & 5.8 & 3.4 & 3.2 & 0.62 \\
\hline Liver disease $(\%)$ & 6.1 & 2.9 & 5.8 & 13.8 & 7.9 & 0.19 \\
\hline Gastrointestinal bleeding (\%) & 6.5 & 3.9 & 7.2 & 10.3 & 7.9 & 0.54 \\
\hline Cancer $(\%)$ & 13.3 & 6.9 & 15.9 & 6.9 & 23.8 & 0.012 \\
\hline RAS inhibitor usage (\%) & 57.8 & 56.9 & 62.3 & 62.1 & 52.4 & 0.66 \\
\hline Statin usage $(\%)$ & 44.1 & 46.0 & 53.6 & 31.0 & 36.5 & 0.10 \\
\hline Height $(\mathrm{cm})$ & $161 \pm 9$ & $163 \pm 8$ & $159 \pm 8$ & $164 \pm 8$ & $157 \pm 9$ & $<0.0001$ \\
\hline Dry weight $(\mathrm{kg})$ & $57.6 \pm 13.4$ & $62.1 \pm 13.1$ & $61.4 \pm 12.2$ & $54.2 \pm 12.6$ & $47.7 \pm 9.2$ & $<0.0001$ \\
\hline Body mass index $\left(\mathrm{kg} / \mathrm{m}^{2}\right)$ & $22.1 \pm 4.2$ & $23.1 \pm 3.8$ & $24.1 \pm 3.9$ & $19.9 \pm 3.3$ & $19.4 \pm 3.5$ & $<0.0001$ \\
\hline Blood urea nitrogen $(\mathrm{mg} / \mathrm{dL})$ & $56.7 \pm 14.2$ & $62.7 \pm 12.8$ & $52.2 \pm 11.8$ & $57.5 \pm 12.7$ & $51.5 \pm 15.7$ & $<0.0001$ \\
\hline Creatinine $(\mathrm{mg} / \mathrm{dL})$ & $9.0 \pm 3.1$ & $11.6 \pm 2.2$ & $6.8 \pm 1.8$ & $10.7 \pm 1.3$ & $6.5 \pm 1.7$ & $<0.0001$ \\
\hline $\mathrm{Alb}(\mathrm{g} / \mathrm{dL})$ & $3.6 \pm 0.4$ & $3.9 \pm 0.3$ & $3.8 \pm 0.3$ & $3.3 \pm 0.3$ & $3.3 \pm 0.4$ & $<0.0001$ \\
\hline $\mathrm{Hb}(\mathrm{g} / \mathrm{dL})$ & $10.6 \pm 1.4$ & $10.8 \pm 1.4$ & $10.5 \pm 1.2$ & $10.4 \pm 1.4$ & $10.3 \pm 1.5$ & 0.23 \\
\hline Total cholesterol (mg/dL) & $148 \pm 33$ & $149 \pm 33$ & $159 \pm 35$ & $135 \pm 30$ & $141 \pm 30$ & 0.0013 \\
\hline Uric acid (mg/dL) & $6.9 \pm 1.7$ & $7.4 \pm 1.8$ & $6.7 \pm 1.5$ & $6.7 \pm 1.7$ & $6.4 \pm 1.8$ & 0.0051 \\
\hline $\mathrm{Ca}(\mathrm{mg} / \mathrm{dL})$ & $8.9 \pm 0.8$ & $9.2 \pm 0.7$ & $8.7 \pm 0.6$ & $8.6 \pm 0.8$ & $8.7 \pm 1.0$ & $<0.0001$ \\
\hline $\mathrm{P}(\mathrm{mg} / \mathrm{dL})$ & $4.9 \pm 1.4$ & $5.4 \pm 1.5$ & $4.5 \pm 1.0$ & $5.3 \pm 1.0$ & $4.4 \pm 1.3$ & $<0.0001$ \\
\hline Intact parathyroid hormone $(\mathrm{pg} / \mathrm{mL})$ & $\begin{array}{c}115 \\
(51-183)\end{array}$ & $\begin{array}{c}116 \\
(50-186)\end{array}$ & $\begin{array}{c}126 \\
(67-185)\end{array}$ & $\begin{array}{c}115 \\
(58-211)\end{array}$ & $\begin{array}{c}100 \\
(29-169)\end{array}$ & 0.59 \\
\hline Glucose (mg/dL) & $144 \pm 62$ & $144 \pm 66$ & $160 \pm 71$ & $130 \pm 44$ & $132 \pm 47$ & 0.046 \\
\hline CRP (mg/dL) & $\begin{array}{c}0.15 \\
(0.06-0.43)\end{array}$ & $\begin{array}{c}0.13 \\
(0.06-0.28)\end{array}$ & $\begin{array}{c}0.12 \\
(0.06-0.35)\end{array}$ & $\begin{array}{c}0.54 \\
(0.11-1.12)\end{array}$ & $\begin{array}{c}0.21 \\
(0.07-1.30)\end{array}$ & 0.0050 \\
\hline $\mathrm{spKt} / \mathrm{V}$ for urea & $1.34 \pm 0.29$ & $1.32 \pm 0.28$ & $1.27 \pm 0.28$ & $1.43 \pm 0.28$ & $1.40 \pm 0.31$ & 0.018 \\
\hline GNRI & $93.1 \pm 7.6$ & $98.1 \pm 3.9$ & $96.7 \pm 3.5$ & $86.0 \pm 4.7$ & $84.4 \pm 6.1$ & $<0.0001$ \\
\hline $\mathrm{mCI}$ & $20.2 \pm 3.0$ & $22.8 \pm 2.2$ & $18.1 \pm 1.4$ & $21.6 \pm 1.3$ & $17.4 \pm 1.7$ & $<0.0001$ \\
\hline
\end{tabular}

(Abbreviations: Alb: albumin, $\mathrm{Hb}$ : hemoglobin, $\mathrm{Ca}$ : calcium, $\mathrm{P}$ : phosphorus, CRP: C-reactive protein GNRI: geriatric nutritional risk index, mCI: modified creatinine index). G1 (group 1), GNRI $\geq 91.2$ and $\mathrm{mCI} \geq 20.16 \mathrm{mg} / \mathrm{kg} /$ day; G2 (group 2), GNRI $\geq 91.2$ and $\mathrm{mCI}<20.16 \mathrm{mg} / \mathrm{kg} /$ day; G3 (group 3), GNRI $<91.2$ and $\mathrm{mCI} \geq 20.16 \mathrm{mg} / \mathrm{kg} /$ day; and G4 (group 4), GNRI $<91.2$ and $\mathrm{mCI}<20.16 \mathrm{mg} / \mathrm{kg} /$ day.

\subsection{Associations of GNRI and $m C I$ with All-Cause Mortality}

A total of 103 deaths were noted during a median follow-up period 3.1 years (1.5-6.0); these included $46(44.7 \%), 30(29.1 \%), 13(12.6 \%)$, and $14(13.6 \%)$ deaths due to cardiovascular disease (19: sudden cardiac death or fatal arrhythmia, 15: congestive heart failure, 9: cerebrovascular accident, and 3: myocardial infarction), infection, malignancies, and other causes, respectively (Figure 1). 
Stable maintenance hemodialysis patients underwent assessment of GNRI and mCI

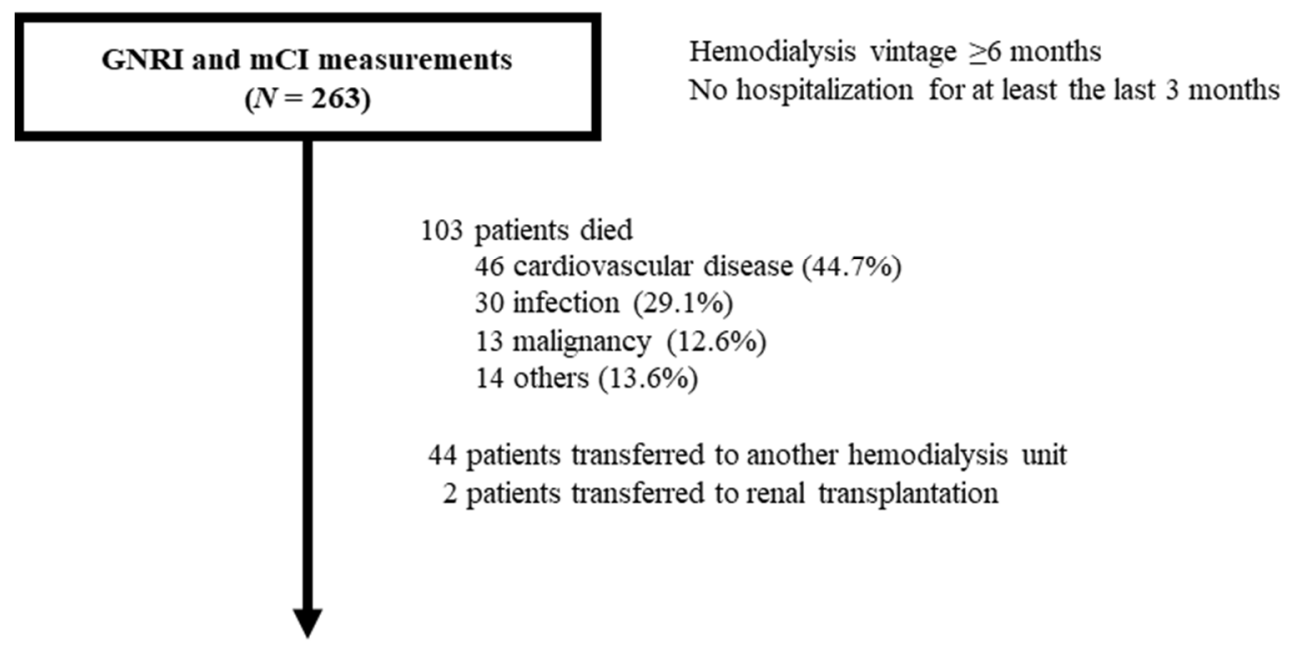

Figure 1. Flow diagram of the present study.

The multivariate Cox regression analysis adjusted by HD vintage, hypertension, the type of vascular access, use of RAS inhibitors and statins, the comorbidity index, hemoglobin level, and log CRP revealed that the GNRI and $\mathrm{mCI}$ were significant indictors for all-cause mortality (GNRI: adjusted HR (aHR), 0.89; 95\% CI, 0.86-0.92, $p<0.0001$; mCI aHR, $0.83 ; 95 \%$ CI, $0.76-0.90, p<0.0001$ ) (Table 2). Among patients divided into two groups using the GNRI cut-off value of 91.2 , the 7-year survival rates were $24.8 \%$ and $68.4 \%$ in those with lower and higher indices, respectively $(p<0.0001)$ (Figure 2a). Similarly, among patients divided into two groups using the $\mathrm{mCI}$ cut-off value of $20.16 \mathrm{mg} / \mathrm{kg} /$ day, the 7 -year survival rates were $39.9 \%$ and $67.7 \%$ in those with lower and higher values, respectively $(p<0.0001)$ (Figure $2 b)$. The aHR for all-cause mortality were 4.96 (95\% CI, 3.10-7.94, $p<0.0001)$ and $1.92(95 \%$ CI, 1.22-3.02, $p=0.0047)$ for low GNRI vs. high GNRI and for low $\mathrm{mCI}$ vs. high $\mathrm{mCI}$, respectively (Table 2 ). With the combined application of both indices, 7-year survival rates were $74.4 \%$ in G1, $57.6 \%$ in G2, 38.7\% in G3, and $20.9 \%$ in G4 $(p<0.0001)$ (Figure 2c). The aHR for G4 vs. G1 was 7.95 (95\% CI, 4.38-14.43, $p<0.0001$ ) (Table 3).

Table 2. Cox analysis of GNRI and mCI for all-cause mortality.

\begin{tabular}{ccccc}
\hline & \multicolumn{2}{c}{ Univariate Analysis } & \multicolumn{2}{c}{ Multivariate Analysis * } \\
\hline Variables & HR (95\% CI) & $p$-Value & HR (95\% CI) & $p$-Value \\
\hline GNRI (continuous) & $0.89(0.87-0.91)$ & $<0.0001$ & $0.89(0.86-0.92)$ & $<0.0001$ \\
mCI (continuous) & $0.81(0.75-0.87)$ & $<0.0001$ & $0.83(0.76-0.90)$ & $<0.0001$ \\
Lower GNRI & $4.26(2.82-6.43)$ & $<0.0001$ & $4.96(3.10-7.94)$ & $<0.0001$ \\
Lower mCI & $2.51(1.68-3.74)$ & $<0.0001$ & $1.92(1.22-3.02)$ & 0.0047 \\
Cross-classified (vs. G1) & & $<0.0001$ & & $<0.0001$ \\
G2 & $1.99(1.16-3.42)$ & 0.013 & $1.11(0.60-2.03)$ & 0.75 \\
G3 & $3.71(1.89-7.27)$ & 0.0001 & $2.75(1.31-5.76)$ & 0.0073 \\
G4 & 7.23 & $<0.0001$ & $(4.95-14.43)$ & $<0.0001$
\end{tabular}

Abbreviations: GNRI: geriatric nutritional risk index, mCI: modified creatinine index. * adjusted by HD vintage, hypertension, the type of vascular access, use of RAS inhibitors and statins, the comorbidity index, hemoglobin level, and $\log$ CRP. 


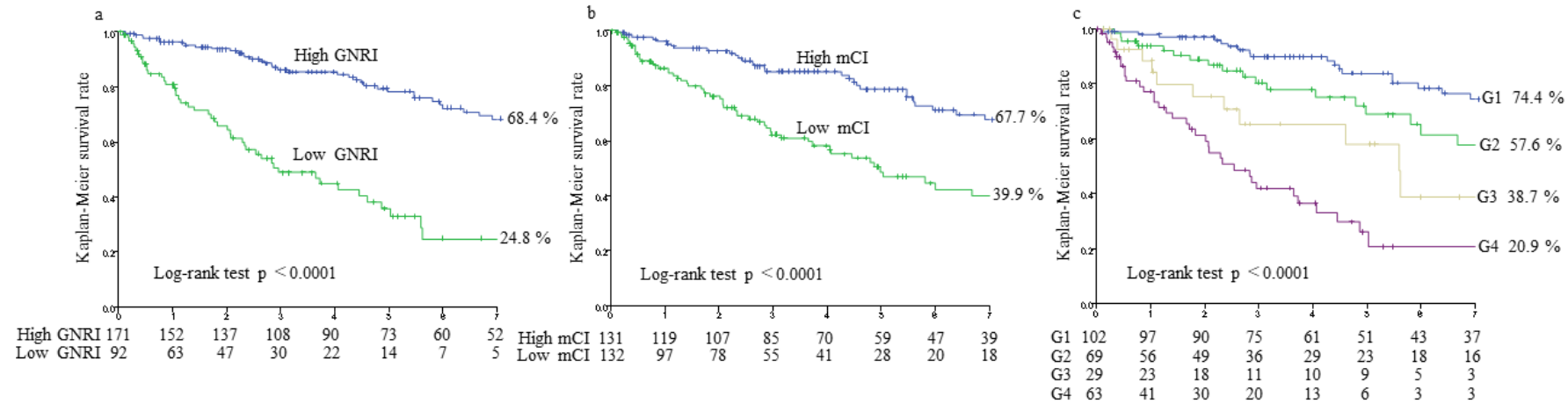

Figure 2. Kaplan-Meier survival curves for all-cause mortality. All-cause mortality rates for two groups of geriatric nutritional risk index (GNRI) $<91.2$ vs. GNRI $\geq 91.2$ (a), two groups of modified creatinine index $(\mathrm{mCI})<20.16 \mathrm{mg} / \mathrm{kg} /$ day vs. $\mathrm{mCI} \geq 20.16 \mathrm{mg} / \mathrm{kg} /$ day $(\mathbf{b})$, and four groups of combined GNRI and $\mathrm{mCI}$ (c). G1 (group 1), GNRI $\geq 91.2$ and $\mathrm{mCI} \geq 20.16 \mathrm{mg} / \mathrm{kg} /$ day; G2 (group 2), GNRI $\geq 91.2$ and $\mathrm{mCI}<20.16 \mathrm{mg} / \mathrm{kg} /$ day; G3 (group 3), GNRI $<91.2$ and $\mathrm{mCI} \geq 20.16 \mathrm{mg} / \mathrm{kg} /$ day; and G4 (group 4), GNRI $<91.2$ and $\mathrm{mCI}<20.16 \mathrm{mg} / \mathrm{kg} /$ day.

Table 3. Predictive accuracies of GNRI and mCI for all-cause mortality.

\begin{tabular}{ccccccc}
\hline Variables & C-Index & $p$-Value & NRI & $p$-Value & IDI & $p$-Value \\
\hline Classical risk factors * & $0.801(0.748-0.855)$ & & Ref. & & 0.0012 & 0.048 \\
+ GNRI & $0.828(0.777-0.878)$ & 0.061 & 0.399 & 0.0012 & 0.00051 \\
+ mCI & $0.822(0.771-0.872)$ & 0.083 & 0.391 & 0.0016 & 0.034 & 0.0028 \\
+ GNRI and mCI & $0.835(0.786-0.884)$ & 0.025 & 0.491 & 0.00006 & 0.058 & 0.0001 \\
\hline
\end{tabular}

Abbreviations: GNRI: geriatric nutritional risk index, $\mathrm{mCI}$ : modified creatinine index, Ref.: reference values. * containing HD vintage, hypertension, the type of vascular access, use of RAS inhibitors and statins, the comorbidity index, hemoglobin level, and log CRP.

\subsection{Model Discrimination in Predicting All-Cause Mortality}

When comparing with a traditional risk model accounting for classical risk indictors (HD vintage, hypertension, type of vascular access, use of RAS inhibitors and statins, the comorbidity index, hemoglobin level, and log CRP), adding the GNRI and $\mathrm{mCI}$ assessment significantly improved the C-index from 0.801 to $0.835(p=0.025)$ (Table 3$)$. The NRI and IDI also significantly improved upon the inclusion of GNRI and $\mathrm{mCI}$ indices in the evaluation $(0.491(p=0.00006)$ and $0.058(p=0.0001)$, respectively) (Table 3).

\section{Discussion}

Lower values of GNRI and $\mathrm{mCI}$ were, as previously reported, independently associated with an increased risk of all-cause mortality, respectively. Further, in the present study, patients on HD in the group of combined lower GNRI and $\mathrm{mCI}$ values were found to be at the highest risk of all-cause mortality. Moreover, the C-index of all-cause mortality significantly improved when the combination of the GNRI and $\mathrm{mCI}$ was added to the baseline model with classical risk indicators. These findings suggested that the combined utilization of both indices could be clinically useful to improve the predictability of all-cause mortality as well as to stratify the risks of all-cause mortality in patients on HD. Therefore, we recommend evaluating both indices at the same time in patients receiving HD.

PEW, a malnutritional state defined by a loss of fat and muscle mass because of catabolic inflammation, is prevalent in patients receiving $\mathrm{HD}$ and is also related to increased risks of mortality [4,21-24]. The MIS proposed by Kalanter-Zadeh et al. is the gold standard method for assessing the nutritional status of HD patients [2]. Although MIS assessment is a useful predictor of morbidity and mortality in this population, its application necessitates subjective evaluations by well-trained examiners [5]. Conversely, the GNRI, which is easily calculable with serum Alb level and BMI [6,8], is an objective tool for the longitudinal assessment of the nutritional status [25]. Yamada et al. reported that there was a negative 
and significant correlation between the GNRI and MIS [6]. They reported 91.2 as the cut-off value of GNRI, which corresponded to malnutrition associated with an MIS > 6 [6]. This cut-off GNRI value was used in the present study. A meta-analysis recently performed by Xiong et al. demonstrated that the GNRI is a clinically useful indictor of predicting all-cause and cardiovascular mortality in patients on HD [10]. Some previous studies showed that the predictive accuracy of MIS was better than that of GNRI [4,5]. However, Chen et al. recently conducted a large cohort study and reported that the predictability of all-cause and cardiovascular mortality of GNRI was comparable to that of MIS [26]. The $\mathrm{mCI}$ is an indicator of muscle wastage and an objective nutritional assessment tool used in HD patients $[7,27,28]$. Hwang et al. reported that the $\mathrm{mCI}$ was correlated with the GNRI [12], and Tsai et al. recently found that the $\mathrm{mCI}$ is an independent predictor of PEW [29]. Furthermore, some studies reported that the $\mathrm{mCI}$ is a useful tool to predict the occurrence of new cardiovascular events and that of infection-associated or all-cause mortality [11-13,30]. Therefore, both the GNRI and mCI are established indicators of PEW and are clinically useful, independent predictors of mortality in patients undergoing HD.

We recently demonstrated that a combined assessment of bio-impedance analysisestimated extracellular fluid/intracellular fluid ratio and GNRI could improve the predictive accuracy for mortality in patients on HD [15]. We also reported that both the erythropoietin resistance index and GNRI were independently correlated with all-cause mortality, and the combined evaluation of these indices improved the predictability of mortality risk in this population [16]. Recently, Yamada et al. showed that the GNRI and $\mathrm{mCI}$ were equally useful tools for predicting all-cause mortality in a patient population receiving HD [14]. We therefore hypothesized that a combination of these indices could improve the predictability of mortality.

In this study, patients with low GNRI and low mCI were independently associated with increased risks of all-cause mortality, respectively. Furthermore, patients with lower values of both GNRI and mCI (G4) demonstrated the highest risk of mortality. Moreover, adding both indices to the baseline evaluation model consisting of classical risk factors led to the significantly improved predictably of all-cause mortality, as observed in the discrimination analysis model. Thus, the combination of GNRI and mCI may be useful to stratify risks of all-cause mortality and to allow clinicians to predict the mortality risk more precisely in patients on HD. The GNRI and mCI employ different evaluation parameters and may be considered surrogate indicators of PEW. Therefore, the simultaneous evaluation of both indices may be recommended as a more robust and accurate clinical assessment tool.

This study has some limitations. First, this is a retrospective, single-center study that included a relatively small number of patients on HD. Because this study is observational, it cannot provide direct cause-and-effect risk associations. Second, the present study only focused on the Japanese population, who are known to have better prognoses compared to those of their counterparts in both the USA and Europe [31]. Therefore, our study results might not be applicable to HD patients in other countries. Third, only the associations of the baseline values of the GNRI and $\mathrm{mCI}$ with all-cause mortality were evaluated; therefore, any changes of these indices were not considered during this study's follow-up period. Moreover, during the follow-up period, 28 patients were treated with an enteral diet, and four patients were temporally treated with intradialytic parenteral nutrition at the discretion of the attending physician. These nutritional therapies might have affected the results of the present study. Fourth, we could not include data on the residual kidney function. The $\mathrm{mCI}$ is developed on the assumption that patients have no residual kidney function; therefore, residual kidney function may affect the $\mathrm{mCI}$ value. To validate our findings, further large-scale, prospective, multicenter studies may be required.

\section{Conclusions}

Low values of GNRI and mCI were independently associated with increased risks of all-cause mortality, and patients on HD with combined low values of both indices demonstrated the highest all-cause mortality risk. The predictability of all-cause mortality 
improved by adding the combined GNRI and $\mathrm{mCI}$ evaluation to the baseline assessment model that included established risk factors. The combined assessment of GNRI and mCI may be clinically helpful to stratify and precisely predict the all-cause mortality risk in patients on HD. Therefore, we propose the simultaneous evaluation of both these indices in patients receiving HD.

Author Contributions: T.Y., K.Y. and M.A., the formulation of the study concept and design; T.Y. and M.A., data collection; T.Y., K.Y. and M.A., data analysis and interpretation; T.Y., draft manuscript; T.Y., K.Y. and M.A., review and revision of the manuscript; T.Y. and M.A., statistical analyses. All authors have read and agreed to the published version of the manuscript.

Funding: No external funding was received.

Institutional Review Board Statement: The study was conducted in accordance with the Declaration of Helsinki. It was approved by the ethics committee of the Matsunami General Hospital (Approval no. 504).

Informed Consent Statement: Patient consent was waived as all the participants' data were anonymized before access.

Data Availability Statement: The data used for analysis in the present study are available upon request to the corresponding author. The data are not publicly available because of privacy or ethical restrictions.

Acknowledgments: All authors thanks Hiroshi Takahashi, BSc, Division of Medical Statistics, Fujita Health University School of Medicine (Aichi, Japan) for his support in the statistical analyses.

Conflicts of Interest: The authors declare no conflict of interest.

\section{References}

1. Fouque, D.; Kalantar-Zadeh, K.; Kopple, J.; Cano, N.; Chauveau, P.; Cuppari, L.; Franch, H.; Guarnieri, G.; Ikizler, T.A.; Kaysen, G.; et al. A proposed nomenclature and diagnostic criteria for protein-energy wasting in acute and chronic kidney disease. Kidney Int. 2008, 73, 391-398. [CrossRef] [PubMed]

2. Kalantar-Zadeh, K.; Kopple, J.D.; Block, G.; Humphreys, M.H. A Malnutrition-Inflammation Score is correlated with morbidity and mortality in maintenance hemodialysis patients. Am. J. Kidney Dis. 2001, 38, 1251-1263. [CrossRef] [PubMed]

3. Rambod, M.; Bross, R.; Zitterkoph, J.; Benner, D.; Pithia, J.; Colman, S.; Kovesdy, C.P.; Kopple, J.D.; Kalantar-Zadeh, K. Association of malnutrition-inflammation score with quality of life and mortality in hemodialysis patients: A 5-year prospective cohort study. Am. J. Kidney Dis. 2009, 53, 298-309. [CrossRef] [PubMed]

4. De Roij van Zuijdewijn, C.L.; ter Wee, P.M.; Chapdelaine, I.; Bots, M.L.; Blankestijn, P.J.; van den Dorpel, M.A.; Nubé, M.J.; Grooteman, M.P. A comparison of 8 nutrition-related tests to predict mortality in hemodialysis patients. J. Ren. Nutr. 2015, 25, 412-419. [CrossRef] [PubMed]

5. Beberashvili, I.; Azar, A.; Sinuani, I.; Kadoshi, H.; Shapiro, G.; Feldman, L.; Averbukh, Z.; Weissgarten, J. Comparison analysis of nutritional scores for serial monitoring of nutritional status in hemodialysis patients. Clin. J. Am. Soc. Nephrol. 2013, 8, 443-451. [CrossRef] [PubMed]

6. Yamada, K.; Furuya, R.; Takita, T.; Maruyama, Y.; Yamaguchi, Y.; Ohkawa, S.; Kumagai, H. Simplified nutritional screening tools for patients on maintenance hemodialysis. Am. J. Clin. Nutr. 2008, 87, 106-113. [CrossRef]

7. Canaud, B.; Granger Vallée, A.; Molinari, N.; Chenine, L.; Leray-Moragues, H.; Rodriguez, A.; Chalabi, L.; Morena, M.; Cristol, J.P. Creatinine index as a surrogate of lean body mass derived from urea $\mathrm{Kt} / \mathrm{V}$, pre-dialysis serum levels and anthropometric characteristics of haemodialysis patients. PLOS ONE 2014, 9, e93286.

8. Yajima, T. Is modified creatinine index really superior to geriatric nutritional risk index for predicting malnutrition and clinical outcomes in hemodialysis patients? J. Ren. Nutr. 2022, S1051-S2276. [CrossRef]

9. Kinugasa, Y.; Kato, M.; Sugihara, S.; Hirai, M.; Yamada, K.; Yanagihara, K.; Yamamoto, K. Geriatric nutritional risk index predicts functional dependency and mortality in patients with heart failure with preserved ejection fraction. Circ. J. 2013, 77, 705-711. [CrossRef]

10. Xiong, J.; Wang, M.; Zhang, Y.; Nie, L.; He, T.; Wang, Y.; Huang, Y.; Feng, B.; Zhang, J.; Zhao, J. Association of geriatric nutritional risk index with mortality in hemodialysis patients: A meta-analysis of cohort studies. Kidney Blood Press. Res. 2018, 43, 1878-1889. [CrossRef]

11. Huang, C.Y.; Lee, S.Y.; Yang, C.W.; Hung, S.C.; Chiang, C.K.; Huang, J.W.; Hung, K.Y. A simpler creatinine index can predict long-term survival in Chinese hemodialysis patients. PLoS ONE 2016, 11, e0165164. [CrossRef] [PubMed] 
12. Hwang, W.; Cho, M.S.; Oh, J.E.; Lee, J.H.; Jeong, J.C.; Shin, G.T.; Kim, H.; Park, I. Comparison of creatinine index and geriatric nutritional risk index for nutritional evaluation of patients with hemodialysis. Hemodial. Int. 2018, 22, 507-514. [CrossRef] [PubMed]

13. Arase, H.; Yamada, S.; Yotsueda, R.; Taniguchi, M.; Yoshida, H.; Tokumoto, M.; Nakano, T.; Tsuruya, K.; Kitazono, T. Modified creatinine index and risk for cardiovascular events and all-cause mortality in patients undergoing hemodialysis: The Q-Cohort study. Atherosclerosis 2018, 275, 115-123. [CrossRef] [PubMed]

14. Yamada, S.; Yamamoto, S.; Fukuma, S.; Nakano, T.; Tsuruya, K.; Inaba, M. Geriatric nutritional risk index (GNRI) and creatinine index equally predict the risk of mortality in hemodialysis patients: J-DOPPS. Sci. Rep. 2020, 10, 5756. [CrossRef] [PubMed]

15. Yajima, T.; Yajima, K.; Takahashi, H.; Yasuda, K. Combined predictive value of extracellular fluid/intracellular fluid ratio and the geriatric nutritional risk index for mortality in patients undergoing hemodialysis. Nutrients 2019, 11, 2659. [CrossRef] [PubMed]

16. Yajima, T.; Yajima, K.; Takahashi, H. Association of the erythropoiesis-stimulating agent resistance index and the geriatric nutritional risk index with cardiovascular mortality in maintenance hemodialysis patients. PLoS ONE 2021, 16, e0245625. [CrossRef]

17. Liu, J.; Huang, Z.; Gilbertson, D.T.; Foley, R.N.; Collins, A.J. An improved comorbidity index for outcome analyses among dialysis patients. Kidney Int. 2010, 77, 141-151. [CrossRef]

18. Beberashvili, I.; Cohen-Cesla, T.; Khatib, A.; Hamad, R.A.; Azar, A.; Stav, K.; Efrati, S. Comorbidity burden may explain adiponectin's paradox as a marker of increased mortality risk in hemodialysis patients. Sci. Rep. 2021, 11, 9087. [CrossRef]

19. Delong, E.R.; Delong, D.M.; Clarke-Pearson, D.L. Comparing the areas under two or more correlated receiver operating characteristic curves: A nonparametric approach. Biometrics 1988, 44, 837-845. [CrossRef]

20. Pencina, M.J.; Agostino, R.B.D.; Vasan, R.S. Evaluating the added predictive ability of a new marker: From area under the ROC curve to reclassification and beyond. Stat. Med. 2007, 27, 157-172, discussion 207. [CrossRef]

21. Yajima, T.; Yajima, K.; Takahashi, H.; Yasuda, K. The impact of abdominal fat levels on all-cause mortality risk in patients undergoing hemodialysis. Nutrients 2018, 10, 480. [CrossRef] [PubMed]

22. Yajima, T.; Arao, M.; Yajima, K.; Takahashi, H.; Yasuda, K. The associations of fat tissue and muscle mass indices with all-cause mortality in patients undergoing hemodialysis. PLoS ONE 2019, 14, e0211988. [CrossRef] [PubMed]

23. Yajima, T.; Arao, M.; Yajima, K.; Takahashi, H. Usefulness of computed tomography-measured psoas muscle thickness per height for predicting mortality in patients undergoing hemodialysis. Sci. Rep. 2021, 11, 19070. [CrossRef] [PubMed]

24. Yajima, T.; Yajima, K.; Takahashi, H. Annual change in the extracellular fluid/intracellular fluid ratio and mortality in patients undergoing maintenance hemodialysis. Sci. Rep. 2022, 12, 242. [CrossRef] [PubMed]

25. Yajima, T.; Yajima, K.; Takahashi, H. Impact of annual change in geriatric nutritional risk index on mortality in patients undergoing hemodialysis. Nutrients 2020, 12, 3333. [CrossRef]

26. Chen, J.; Qin, X.; Li, Y.; Yang, Y.; Yang, S.; Lu, Y.; Zhao, Y.; He, Y.; Li, Y.; Lei, Z.; et al. Comparison of three nutritional screening tools for predicting mortality in maintenance hemodialysis patients. Nutrition 2019, 67, 110532. [CrossRef]

27. Canaud, B.; Ye, X.; Usvyat, L.; Kooman, J.; van der Sande, F.; Raimann, J.; Wang, Y.; Kotanko, P. Clinical and predictive value of simplified creatinine index used as muscle mass surrogate in end-stage kidney disease haemodialysis patients-results from the international MONitoring Dialysis Outcome initiative. Nephrol. Dial. Transplant. 2020, 35, 2161-2171. [CrossRef]

28. Yamamoto, S.; Matsuzawa, R.; Hoshi, K.; Suzuki, Y.; Harada, M.; Watanabe, T.; Isobe, Y.; Imamura, K.; Osada, S.; Yoshida, A.; et al. Modified creatinine index and clinical outcomes of hemodialysis patients: An indicator of sarcopenia? J. Ren. Nutr. 2021, 31, 370-379. [CrossRef]

29. Tsai, M.T.; Tseng, W.C.; Ou, S.M.; Lee, K.H.; Yang, C.Y.; Tarng, D.C. Comparison of simplified creatinine index and systemic inflammatory markers for nutritional evaluation of hemodialysis patients. Nutrients 2021, 30, 1870. [CrossRef]

30. Arase, H.; Yamada, S.; Hiyamuta, H.; Taniguchi, M.; Tokumoto, M.; Tsuruya, K.; Nakano, T.; Kitazono, T. Modified creatinine index and risk for long-term infection-related mortality in hemodialysis patients: Ten-year outcomes of the Q-Cohort study. Sci. Rep. 2020, 10, 1241. [CrossRef]

31. Robinson, B.M.; Bieber, B.; Pisoni, R.L.; Port, F.K. Dialysis Outcomes and Practice Patterns Study (DOPPS): Its strengths, limitations, and role in informing practices and policies. Clin. J. Am. Soc. Nephrol. 2012, 7, 1897-1905. [CrossRef] [PubMed] 